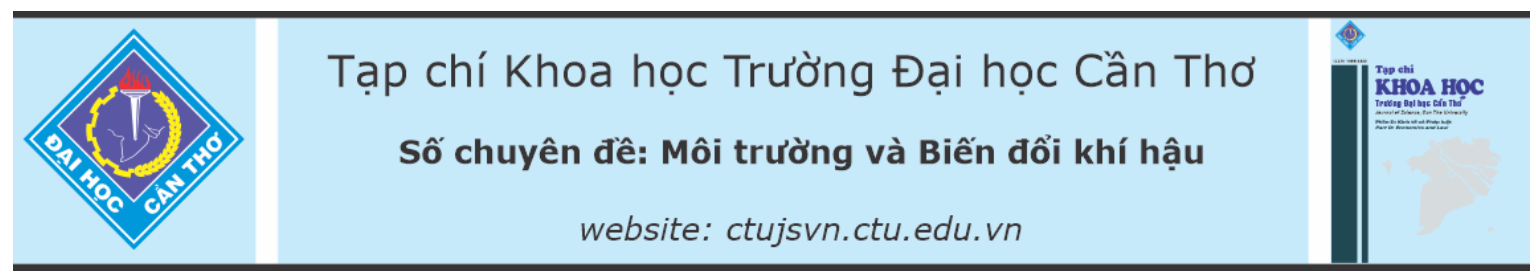

DOI:10.22144/ctu.jsi.2021.035

\title{
TÁI SỬ DỤNG ỐNG HÚT NHỰA LÀM GIÁ THỂ TRONG BỂ LỌC SINH HỌC NGGẬP NƯỚC ĐỂ XỬ LÝ NƯỚC THẢI SINH HOẠT
}

\author{
Kim Lavane ${ }^{*}$ Nguyễn Trường Thành và Phạm Văn Toàn \\ Khoa Môi truờng và Tài nguyên Thiên nhiên, Truờng Đại học Cần Tho \\ *Nguoòi chịu trách nhiệm về bài viết: Kim Lavane (email: klavane@ ctu.edu.vn)
}

\section{Thông tin chung:}

Ngày nhận bài: $12 / 04 / 2021$

Ngày nhận bài sủa: 17/09/2021

Ngày duyệt đăng: 15/11/2021

\section{Title:}

Reusing plastic straws as carrier in a submerged biofilter to treat domestic wastewater

\section{Tù khóa:}

Hiệu suất xủ lý, loc sinh họ, màng sinh học, nuớc thải sinh hoạt, ống hút nhưa

\section{Keywords:}

Biofilm, biological filter, domestic wastewater, plastic straw, removal efficiency

\begin{abstract}
The objective of the study was to assess the potential use of plastic straws as carrier in a submerged biological filter for domestic wastewater treatment. Used plastic straws were collected and formed into a cylindrical block media with a length of $2.5 \mathrm{~cm}$ and a diameter of $1.8 \mathrm{~cm}$ for biofilm growth. Two identical biological filters were designed with an LxWxH dimension of 0.15 $m \times 0.15 \mathrm{~m} \times 1.2 \mathrm{~m}$. The total medium height $(0.7 \mathrm{~m})$ was kept immobile and completely submerged in wastewater with $0.25 \mathrm{~m}$ from the bottom and to the open surface of the reactor. Two filters were operated in parallel. The hydraulic retention times (HRT) were $5 \mathrm{~h}$ and $6 \mathrm{~h}$ for the aerated filter and 6 $h$ and $8 h$ for the non-aerated filter. Experimental results showed that the effluent concentrations of TSS, $\mathrm{BOD}, \mathrm{COD}, \mathrm{N}-\mathrm{NO}_{3}{ }^{-}, \mathrm{TP}, \mathrm{P}_{-} \mathrm{PO}_{4}{ }^{3-}$ of the two biological filters in this study met type A QCVN 14:2008/BTNMT, except for $\mathrm{N}-\mathrm{NH}_{4}{ }^{+}$. When the hydraulic retention time increased to 6 hours in the aerated filter, the removal efficiency increased and the $\mathrm{N}-\mathrm{NH}_{4}{ }^{+}$reached type $B Q C V N$ 14:2008/BTNMT. The biological filter without aeration had higher $\mathrm{N}-\mathrm{NO}_{3}$ removal rate than the aerated filter, but other parameters were in reverse. In short, used plastic straws can be reused to serve as the carrier in the submerged biological filters for domestic wastewater treatment.
\end{abstract}

\section{TÓM TẮT}

Mục tiêu của nghiên cưu nhằm đánh giá tiềm năng sử dụng ống hút nhựa làm giá thể trong bể lọc sinh học (LSH) ngập nước để xư lý nuớc thải sinh hoạt. Ông hút nhưa đã qua sử dụng được thu thập và tạo thành khối hình tru có chiều dài $2,5 \mathrm{~cm}$ và đường kính $1,8 \mathrm{~cm}$ làm giá thể cho vi sinh vật phát triển thành màng sinh học. Hai mô hình bể LSH được thiết kế giống nhau có kich thuơóc DxRxC là 0,15 $m \times 0,15 m \times 1,2 \mathrm{~m}$. Tổng chiều cao giá thể $(0,7 \mathrm{~m})$ được giữ cố định và ngập hoàn toàn trong nước thải, cách đáy bể và măt thoáng lần lượt 0,25 $\mathrm{m}$. Hai bể LSH được vận hành song song với một bể cấp không khí liên tuc có thời gian luu nước (HRT) lần luợt 5 giờ và 6 giờ và bể còn lại không cấp không khi có HRT lần luợt 6 giờ và 8 giờ. Kết quả thí nghiệm cho thấy nồng độ các chỉ tiêu TSS, $\mathrm{BOD}, \mathrm{COD}, \mathrm{N}-\mathrm{NO}_{3}{ }^{-}, \mathrm{TP}, \mathrm{P}-\mathrm{PO}_{4}{ }^{3-}$ đầu ra của hai bể trong nghiên cứu này đều đạt loại A QCVN 14:2008/BTNMT ngoại trùu chi tiêu $\mathrm{N}-\mathrm{NH}_{4}{ }^{+}$. Khi HRT của bể LSH có cấp không khi kéo dài 6 giờ thì hiệu suất xủ lý tăng và chỉ tiêu $N-N_{4}{ }^{+}$đạt loại $B$ QCVN 14:2008/BTNMT. Bể LSH không cấp không khí có hiệu suất xử lý $\mathrm{N}-\mathrm{NO}_{3}{ }^{-}$cao hơn bể có cấp không khí nhung đối với các chỉ tiêu khác thì ngược lại. Nhìn chung, ống hút nhựa đã qua sư dụng có thể tái sử dụng để làm giá thể vi sinh trong LSH ngập nước để xử lý nước thải sinh hoạt. 


\section{GIỚI THIỆU}

Nước thải sinh hoạt (NTSH) là nước thải ra từ các hoạt động sinh hoạt của con người như ăn uống, tắm giặt, vệ sinh cá nhân. NTSH thường chứa các chất hữu cơ, dinh dưỡng, chất rắn lơ lửng, dầu mỡ, các chất hoạt động bề mặt, các chất ô nhiễm dạng vết như các sản phẩm chăm sóc sức khỏe con nguời, và các vi sinh vật gây bệnh cũng như các vi sinh vật khác (Nguyễn Văn Phước, 2014; Oliveira et al., 2021). Các tạp chất khác nhau trong NTSH chứa $52 \%$ chất hữu cơ và $48 \%$ chất vô cơ (Nguyễn Văn Phước, 2014). Theo Báo cáo Hiện trạng môi trường quốc gia 2018, chỉ có $12,5 \%$ lượng NTSH tại các đô thị ở Việt Nam (loại IV trở lên) được xử lý đạt tiêu chuẩn qui định. Tại vùng Đồng bằng sông Cửu Long, NTSH phần lớn được xả trực tiếp ra môi trường mà không được xử lý triệt để (Bộ Tài nguyên và Môi trường, 2018). Do đó, những vấn đề này gây ra điều kiện vệ sinh môi trường ở nông thôn thấp và NTSH không được xử lý hợp lý gây ra ô nhiễm nguồn nước ngày càng nghiêm trọng.

Lọc sinh học (LSH) là một công nghệ xử lý sinh học được nghiên cứu và áp dụng để loại bỏ các chất hữu cơ và dinh dưỡng dựa vào sự phát triển của màng sinh học trên bề mặt giá thể. Một số nghiên cứu trong nước cho thấy LSH có giá thể ngập nước có thể áp dụng hiệu quả để xử lý nhiều nguồn nước thải khác nhau. Nghiên cứu của Lê Hoàng Việt và ctv. (2015) cho thấy LSH hiếu khí có giá thể ngập nước có thể xử lý nước thải thủy sản với hiệu suất rất cao và nước thải sau xử lý đạt qui chuẩn cho phép xả thải. LSH ngập nước có thể xử lý chất ô nhiễm trong nước thải ao nuôi thủy sản nước lợ (Phạm Thị Hồng Ngân \& Phạm Khắc Liệu, 2012) và nước thải sản xuất tinh bột mì (Nguyễn Thị Thanh Phượng và ctv., 2010).

Có rất nhiều loại giá thể công nghiệp được sử dụng để nghiên cứu trong hệ thống LSH. Lê Hoàng Việt và ctv. (2015) đã sử dụng các vật liệu tự chế khác nhau làm giá thể. Tuy nhiên, số lượng các nghiên cứu sử dụng giá thể tái chế từ ống hút nhựa rất ít. Gốm sứ và nhựa từ chất thải rắn được tái sử dụng làm giá thể trong hệ thống LSH (Osorio \& Hontoria, 2002). Nguyễn Thị Thanh Phượng và ctv. (2010) cũng đã nghiên cứu sử dụng các loại vật liệu khác nhau như xơ dừa, than đá, giá thể dạng cầu (bioball) và nhựa $\mathrm{PE}$ (polyethylene) làm giá thể trong bể LSH hiếu khí ngập nước.

Một nghiên cứu gần đây cho thấy rằng 380 triệu tấn các sản phẩm nhựa được sản xuất trong năm 2015 (Geyer et al., 2017). Một nửa trong các sản phẩm nhựa là những sản phẩm dùng một lần như túi nhựa, cốc và ống hút (Science for Environment Policy, 2011). Việt Nam xếp vị trí thứ tư sau Trung Quốc, Indonesia, và Philippines trong số 20 quốc gia hàng đầu phát thải rác thải nhựa (Jenna et al., 2015). Theo báo cáo của Vụ quản lý chất thải thuộc Tổng cục Môi trường (2019), chất thải nhựa không có hoặc có giá trị tái chế thấp gồm túi nilon, hộp xốp các loại, và ống hút nhựa thường bị thải bỏ. Ống hút nhựa có độ bền cao và có khối lượng riêng 705-855 $\mathrm{kg} / \mathrm{m}^{3}$ (Gutierrez et al., 2019). Tái sử dụng ống hút nhựa làm giá thể trong hệ thống LSH để xử lý nước thải có thể mang lại lợi ích kép là vừa xử lý nước thải vừa giảm thiểu phát thải chất thải nhựa ra môi trường. Do đó, mục tiêu của nghiên cứu này là: 1 ) thử nghiệm hiệu quả của hệ thổng LSH ngập nước khi sử dụng ống hút nhựa làm giá thể màng sinh học để xử lý NTSH, 2) đánh giá ảnh hưởng của thời gian lưu nước lên hiệu suất xử lý, 3 ) so sánh hiệu suất xử lý với điều kiện vận hành có cấp không khí và không cấp không khí.

\section{VÂTT LIÊUU VÀ PHƯƠNG PHÁP}

\subsection{Mô hình thí nghiệm}

Các thí nghiệm được tiến hành trên mô hình quy mô phòng thí nghiệm. Mô hình nghiên cứu được thiết kế bằng vật liệu thủy tinh với các kích thước dựa theo mô hình bể LSH hiếu khí ngập nước trong một nghiên cứu của Lê Hoàng Việt và ctv. (2015). Các thông số kích thước cơ bản của mô hình được trình bày trong Bảng 1 .

Bảng 1. Kích thước mô hình bể LSH ngập nước

\begin{tabular}{lr}
\hline Thông số & Giá trị \\
\hline Kích thước trong mặt đáy $(\mathrm{m} \times \mathrm{m})$ & $0,15 \times 0,15$ \\
Chiều cao mô hình $(\mathrm{m})$ & 1,2 \\
Chiều cao lớp giá thề $(\mathrm{m})$ & 0,7 \\
Tồng thể tích hữu dụng $(\mathrm{L})$ & 27 \\
Thể tích vận hành $(\mathrm{L})$ & 23,6 \\
\hline
\end{tabular}

Ống hút nhựa được ngâm và rửa bằng nước sạch, sau đó để khô ở nhiệt độ phòng thí nghiệm và được cắt thành đoạn ngắn có chiều dài $2,5 \mathrm{~cm}$. Các đoạn ngắn sau đó được gắn lại với nhau bằng keo dán 502 tạo thành khối có tổng đường kính trung bình khoảng 1,8 cm (Hình 2).

Độ rỗng của giá thể được đo tương đối bằng phương pháp bão hòa nước (Etnyre, 1989). Cụ thể, các giá thể được sắp ngẫu nhiên vào đầy cốc thủy tinh dung tích $1.000 \mathrm{~mL}\left(\mathrm{~V}_{\mathrm{T}}=1 \mathrm{~L}\right)$. Một lít nước cất được sử dụng để rót từ từ vào cốc chứa giá thể để lấp đầy thể tích rỗng trong khối giá thể cho đến khi giá thể ngập hoàn toàn và sau đó xác định thể tích 
nước thừa còn lại bằng ống đong. Thể tích rỗng của giá thể là thể tích nước đã đổ vào cốc. Độ rỗng của giá thể ống hút trong thí nghiệm được xác định từ giá trị trung bình của 5 lần lặp lại và được tính bằng công thức sau:

$$
p=\frac{V_{r}}{V_{T}}
$$

Trong đó:

$$
\begin{aligned}
& \text { p: độ rỗng }(\%) \\
& \text { Vr: thể tích rỗng }(\mathrm{L}) \\
& \mathrm{V}_{\mathrm{T}} \text { : thể tích tổng của khối giá thể }(\mathrm{L})
\end{aligned}
$$

Tổng diện tích bề mặt của giá thể trên đơn vị thể tích $\left(\mathrm{S}: \mathrm{m}^{2} / \mathrm{m}^{3}\right)$ được xác định dựa theo cách tính toán tổng bề mặt của mỗi giá thể. Tổng bề mặt của mỗi giá được tính toán thông qua tổng diện tích mặt trong và mặt ngoài của 5 đoạn ống hút nhựa dài 2,5 $\mathrm{cm}$ sử dụng để tạo ra một giá thể. Do số lượng giá thể được chuẩn bị vừa đủ để xây dựng mô hình nên tổng diện tích bề mặt được tính cho một thể tích đơn vị $10 \mathrm{~L}$ và sau đó suy ra theo đơn vị thể tích $\mathrm{m}^{3}$.

$$
S=n \times A
$$

Trong đó:

$\mathrm{S}$ : tổng diện tích bề mặt trong một thể tích đơn vị $\left(\mathrm{m}^{2} / \mathrm{m}^{3}\right)$

n: số lượng giá thể trong $10 \mathrm{~L}$ (giá thể)

A: diện tích bề mặt của mỗi giá thể ( $\mathrm{m}^{2} /$ giá thể)

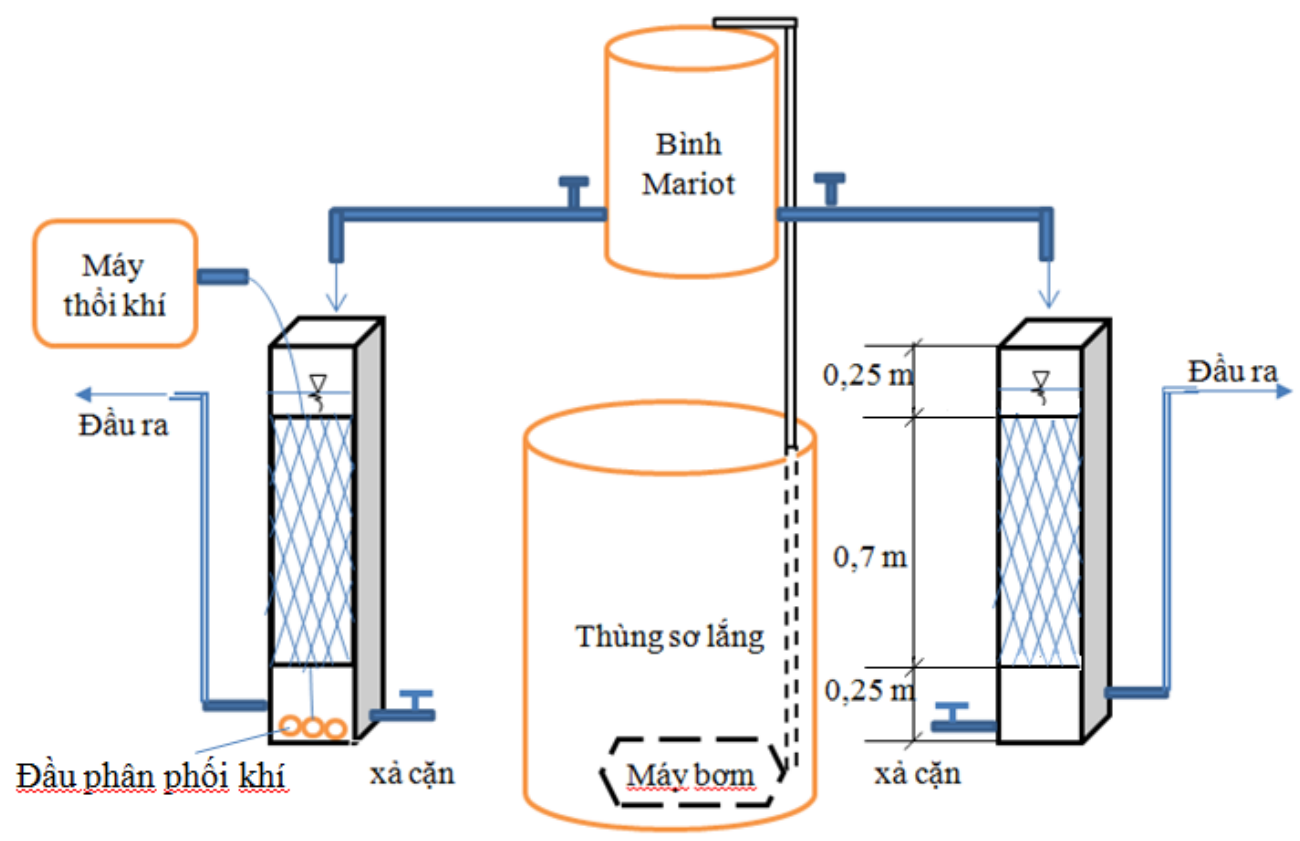

\section{Hình 1. Sơ đồ mô hình thí nghiệm}

\subsection{Xác định thành phần nước thải}

NTSH sử dụng trong các thí nghiệm được thu tại cống xả ra bờ kè Rạch Tham Tướng (có tọa độ: $10^{\circ} 01^{\prime} 43^{\prime \prime} \mathrm{N} 105^{\circ} 46^{\prime} 17^{\prime}$ 'E), đường Mạc Thiên Tích, phường Xuân Khánh, quận Ninh Kiều, Thành phố Cần Thơ). Thời gian lây mẫu dao động vào khoảng 9 - 10 giờ sáng.

Thành phần và tính chất NTSH khi thu mẫu biến động giữa các ngày khác nhau phụ thuộc vào số lượng người dân sử dụng nước ban đầu. Việc xác định thành phần, tính chất nước thải ban đầu rất cần thiết. Do đó, mẫu nước thải được thu thập và phân tích các chỉ tiêu gồm $\mathrm{pH}, \mathrm{DO}, \mathrm{TSS}, \mathrm{COD}, \mathrm{BOD}_{5}$, $\mathrm{N}-\mathrm{NO}_{3}{ }^{-}, \mathrm{N}-\mathrm{NH}_{4}{ }^{+}, \mathrm{P}_{-} \mathrm{PO}_{4}{ }^{3-}$ và $\mathrm{TP}$ trong 5 ngày liên tiếp.

\subsection{Các bước tiến hành thí nghiệm trên mô hình}

\subsubsection{Tiền xử lý nước thải đầu vào}

NTSH ban đầu được tiền xử lý bằng cách để lắng tĩnh 30 phút trong thùng lắng nhằm loại bỏ rác, một số chất rắn nổi có kích thước lớn và chất rắn lắng được trước khi bơm vào bình Mariot để phân phối nạp vào mô hình LSH qua mặt thoáng (Hình 1). 


\subsubsection{Khởi động và vận hành bể LSH}

Màng sinh học trên giá thể ống hút nhựa được thúc đẩy phát triển bằng cách ngâm giá thể trong nước thải thủy sản và sục khí liên tục trong 2 tuần. Sau khi giá thể có sự thay đổi màu sắc sang màu nâu và quan sát thấy xuất hiện lớp màng sinh học dính bám trên giá thể thì vớt giá thể ra và đặt vào mô hình LSH (Hình 2B). NTSH sau khi tiền xử lý được nạp vào mô hình từ bình Mariot và tiến hành chạy khởi động để ổn định sự phát triển màng sinh học trên bề mặt giá thể. Thời gian lưu nước trong hệ thống trong quá trình chạy khởi động là 6 giờ. Đối với cột LSH hiếu khí, không khí được cấp vào liên tục với lưu lượng $30 \mathrm{~L} /$ phút qua hệ thống phân phối khí dạng đĩa đá bọt từ đáy bể. Trong khi đó, bể LSH còn lại không cẩp khí trong quá trình vận hành. Trong thời gian chạy khởi động, chỉ tiêu COD trong nước thải đầu ra của mô hình được theo dõi thường xuyên cho đến khi nồng độ của chúng ổn định hoặc ít biến động giữa các lần quan trắc thì tiến hành thí nghiệm chính thức để đánh giá hiệu quả xử lý của bể LSH.

Đánh giá hiệu quả xử lý NTSH trên mô hình LSH được tiến hành lần lượt với HRT 6 giờ và 5 giờ đối với thí nghiệm cấp khí, HRT 6 giờ và 8 giờ đối với thí nghiệm không cấp khí. Sau thời gian chạy ổn định, cả hai mô hình được vận hành chính thức với thời gian lưu nước như nhau (HRT 6 giờ). Nước thải sau xử lý được quan trắc liên tục trong 3 ngày với các chỉ tiêu gồm $\mathrm{pH}, \mathrm{DO}, \mathrm{TSS}, \mathrm{COD}, \mathrm{BOD}_{5}, \mathrm{TKN}$, $\mathrm{N}-\mathrm{NH}_{4}{ }^{+}, \mathrm{N}-\mathrm{NO}_{3}{ }^{-}, \mathrm{TP}, \mathrm{PO}_{4}{ }^{3-}$. Tiếp theo, HRT của 2 mô hình được thay đổi, trong đó HRT giảm xuống 5 giờ đối với LSH có cấp khí và HRT tăng lên 8 giờ đối với LSH không cấp khí. Nước thải sau xử lý được quan trắc liên tục trong 3 ngày với các chỉ tiêu phân tích tương tự như trên.

\subsection{Phân tích và xử lý số liệu}

Phương pháp phân tích các chỉ tiêu được dựa theo qui chuẩn hiện hành và thực hiện tại phòng thí nghiệm Hóa Môi trường, Khoa Môi trường và Tài nguyên thiên nhiên, Trường Đại học Cần Thơ. Chỉ tiêu $\mathrm{pH}$ và $\mathrm{DO}$ được đo trực tiếp bằng thiết bị đo nhanh. Phương pháp khối lượng được sử dụng để xác định TSS (TCVN 6625:2000). BOD 5 được xác định bằng phương pháp Winkler cải tiến (TCVN 6001:2008), COD được xác định bằng phương pháp Dicromate đun hoàn lưu kín (TCVN 6491:1999), TKN và $T P$ được xác định theo qui trình của SMEWW 4500-N và 4500-P (APHA, 2005). N$\mathrm{NH}_{4}{ }^{+}$được xác định theo phương pháp chưng cất và

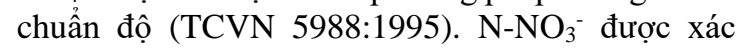
định theo phương pháp Salycylate (TCVN

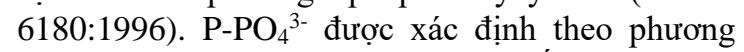
pháp so màu (TCVN 6202:2008). Số liệu các chỉ tiêu trong nước thải trước và sau xử lý được tính giá trị trung bình và độ lệch chuẩn bằng phầm mềm ứng dụng Microsoft Excel 2007. So sánh trung bình hiệu suất giữa các điều kiện vận hành của mô hình theo phương pháp Kiểm định T-test bằng phần mềm SigmaPlot 10.0.

\section{KẾT QUẢ VÀ THẢO LUẬN}

\subsection{Thông số vật lý của giá thể ống hút nhựa}

Giá thể ống hút nhựa được tạo hình như dạng tổ ong (Hình 2A). Trước khi cho vào mô hình thí nghiệm, một số thông số cơ bản giá thể ống hút nhựa được xác định và được trình bày trong Bảng 2 .

Bảng 2. Các thông số kỹ thuật của giá thể ống hút nhựa

\begin{tabular}{lr}
\hline Thông số & Giá trị \\
\hline Chiều dài đoạn giá thể $(\mathrm{cm})$ & 2,5 \\
Đường kính lỗ của giá thể $(\mathrm{cm})$ & 1,8 \\
Đồ rỗng $(\%)$ & $71,8 \pm 1,9$ \\
Tồng diện tích bề mặt $\left(\mathrm{m}^{2} / \mathrm{m}^{3}\right)$ & $453 \pm 7,6$ \\
\hline
\end{tabular}

Sau thời gian nuôi màng sinh học, có thể thấy rằng, vi sinh vật phát triển và tạo thành một lớp màng trên bề mặt giá thể. Theo nghiên cứu của Lê Hoàng Việt và ctv. (2015), giá thể sinh học sau khi được nuôi bằng nước thải thủy sản thì vi sinh vật phát triển nhanh và tạo thành màng ổn định do nước thải thủy sản có chứa nhiều dưỡng chất cần thiết cho vi sinh vật phát triển. Trong nghiên cứu này, thời gian nuôi cấy ban đầu để màng sinh học phát triển là 2 tuần (Hình 2B). 

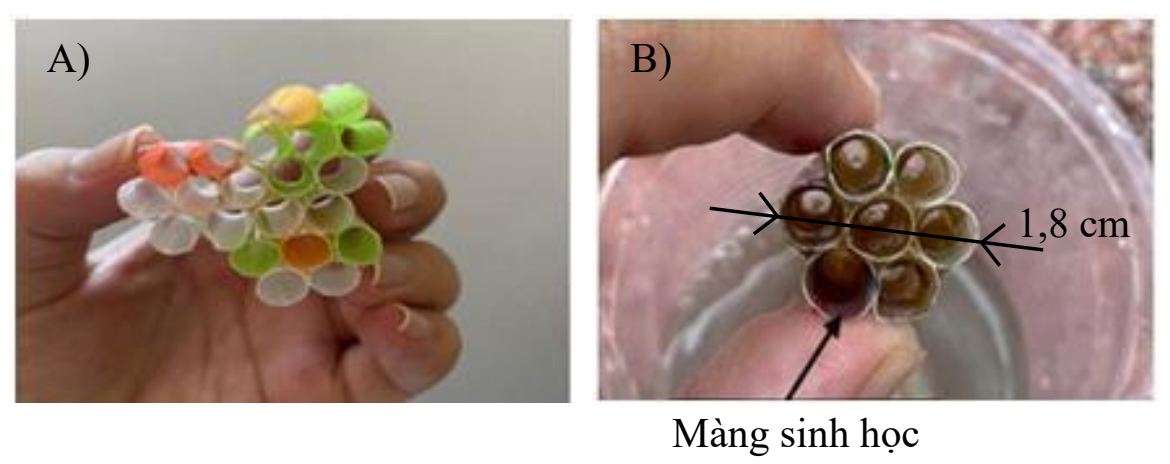

Hình 2: Giá thể ống hút nhựa: (A) trước thí nghiệm, (B) có màng sinh học phát triển

\subsection{Tính chất NTSH đầu vào}

Nhìn chung, NTSH đầu vào được quan trắc trong 5 ngày liên tục cho thấy phù hợp để áp dụng biện pháp xử lý sinh học. Giá trị trung bình của các chỉ tiêu được trình bày trong Bảng 3 .

\section{Bảng 3. Đặc điểm NTSH đầu vào}

\begin{tabular}{cllr}
\hline STT & Chỉ tiêu & Đơn vị & $\begin{array}{r}\text { Nồng độ trị trung } \\
\text { bình }(\mathbf{n}=\mathbf{5})\end{array}$ \\
\hline 1 & $\mathrm{pH}$ & - & $6,9 \pm 0,2$ \\
2 & $\mathrm{DO}$ & $\mathrm{mg} / \mathrm{L}$ & $0,4 \pm 0,1$ \\
3 & $\mathrm{TSS}$ & $\mathrm{mg} / \mathrm{L}$ & $44,3 \pm 10,8$ \\
4 & $\mathrm{COD}$ & $\mathrm{mg} / \mathrm{L}$ & $236,9 \pm 25,1$ \\
5 & $\mathrm{BOD}$ & $\mathrm{mg} / \mathrm{L}$ & $124,2 \pm 9,9$ \\
6 & $\mathrm{TKN}$ & $\mathrm{mg} / \mathrm{L}$ & $23,8 \pm 2,1$ \\
7 & $\mathrm{~N}-\mathrm{NH}_{4}{ }^{+}$ & $\mathrm{mg} / \mathrm{L}$ & $23,3 \pm 3,0$ \\
8 & $\mathrm{~N}-\mathrm{NO}_{3}{ }^{-}$ & $\mathrm{mg} / \mathrm{L}$ & $0,5 \pm 0,3$ \\
9 & $\mathrm{TP}$ & $\mathrm{mg} / \mathrm{L}$ & $1,9 \pm 0,5$ \\
10 & $\mathrm{P}_{-} \mathrm{PO}_{4}{ }^{3-}$ & $\mathrm{mg} / \mathrm{L}$ & $0,3 \pm 0,3$ \\
\hline
\end{tabular}

Kết quả cho thấy giá trị pH trung bình là 6,9 và nằm trong khoảng giá trị phù hợp cho sự phát triển của vi sinh vật trong hệ thống xử lý sinh học $(\mathrm{pH}$ : $6,5 \div 8,5)$ (Nguyễn Văn Phước, 2014). Tỉ số $\frac{\mathrm{BOD}_{5}}{\mathrm{COD}}$ là $0,52>0,5$ nên nước thải này thích hợp cho quá trình xử lý sinh học. Nồng độ TKN đạt $24 \pm 2 \mathrm{mg} / \mathrm{L}$ và TP đạt $2 \pm 0,5 \mathrm{mg} / \mathrm{L}$ cho thấy tỉ lệ giữa carbon và chất dinh dưỡng trong nước thải tính theo tỉ lệ $\mathrm{BOD}_{5}$ : N : P là 124,2 : 24 : 2,0. Theo Nguyễn Văn Phước (2014), tỉ lệ này yêu cầu 100: 5: 1 là thích hợp cho vi sinh vật phát triển. Như vậy, vì NTSH ban đầu có lượng nitơ và phosphor cao hơn so với nhu cầu của vi sinh vật cần nên nó hoàn toàn thích hợp cho vi sinh vật. Đây là các chất dinh dưỡng cơ bản cho vi sinh vật hấp thu để thúc đẩy sự sinh trưởng. Do đó, hoạt động chuyển hóa chất ô nhiễm của các vi sinh vật trong mô hình xử lý không bị hạn chế bởi sự thiếu hụt cơ chất.

\section{3. Đánh giá nồng độ các chỉ tiêu trong nước thải sau xử lý}

Nồng độ các chỉ tiêu sau xủ lý đuợc trình bày trong Bảng 4. Kết quả cho thấy mô hình LSH ngập nước sử dụng giá thể ống hút nhựa có cấp khí và không cấp khí đều xử lý đạt hiệu quả cao. Đối với thí nghiệm có cấp khí, hầu hết nồng độ các đầu ra đạt QCVN 14:2008/BTNMT (cột $\mathrm{A}$ ), ngoại trừ chỉ tiêu $\mathrm{N}-\mathrm{NH}_{4}{ }^{+}$. Nồng độ $\mathrm{N}-\mathrm{NO}_{3}{ }^{-}$trong nước sau xử lý cao hơn đầu vào. Sự gia tăng nồng độ $\mathrm{N}-\mathrm{NO}_{3}{ }^{-}$trong nước thải sau xử lý là do quá trình nitrate hóa diễn ra. Sự chuyển hóa $\mathrm{N}-\mathrm{NH}_{4}{ }^{+}$sang $\mathrm{N}-\mathrm{NO}_{3}{ }^{-}$tăng tương ứng với thời gian lưu nước. Kết quả cho thấy ở thời gian lưu nước 6 giờ thì nồng độ $\mathrm{N}-\mathrm{NH}_{4}{ }^{+}$tiếp tục giảm nhưng $\mathrm{N}^{-\mathrm{NO}_{3}}{ }^{-}$lại gia tăng. Điều này cho thấy quá trình nitrate hóa diễn ra mạnh trong mô hình xử lý. Tương tư nhu kết quả nghiên cứu của Lê Hoàng Việt và ctv. (2015), bể LSH hiếu khí có thể loại bỏ $\mathrm{NH}_{4}{ }^{+}$trong nước thải chế biến cá tra đạt tiêu chuẩn xả thải úng với HRT 8 giò̀, trong khi nồng độ $\mathrm{N}-\mathrm{NO}_{3}{ }^{-}$ trong nước thải sau xủ lý gia tăng.

Thí nghiệm không cấp khí có chất lượng nước sau xử lý kém hơn thí nghiệm có cấp không khí. Bảng 3 cho thấy đa số nồng độ của các chỉ tiêu đầu ra của thí nghiệm không cấp không khí đều cao hơn so với thí nghiệm có cấp khí, ngoại trừ chỉ tiêu N$\mathrm{NO}_{3}^{-}$. Điều này có thể do hệ thống không cấp khí thiếu hụt ôxy hòa tan nên quá trình ôxy hóa sinh hóa các hợp chất hữu cơ trong bể diễn ra chậm. Tuy

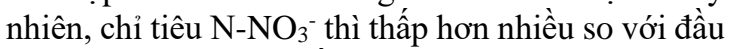
ra của mô hình có cấp không khí và đạt $\mathrm{QCVN}$ 08:2008/BTNMT (cột $A 1$ và $A 2$ ). Kết quả này cho thấy quá trình khử nitrate diễn ra tốt trong bể không cấp khí. So với bể có cấp khí, sự chuyển hóa $\mathrm{N}_{-} \mathrm{NH}_{4}{ }^{+}$ sang ${\mathrm{N}-\mathrm{NO}_{3}}^{-}$của bể không cấp khí thấp. Hàm lượng ôxy hòa tan thấp có thể là nguyên nhân chính hạn chế ôxy hóa sinh học các chỉ tiêu khác, nhưng là điều kiện thúc đẩy quá trình khử nitrate diễn ra tốt hơn. Kiểm soát ôxy hòa tan là một trong những yếu tố cho quá trình xử lý nitơ một cách hiệu quả trong hệ 
thống LSH. Gajewska et al. (2020) cho rằng quá trình nitrate hóa diễn ra hiệu quả hơn trong hệ thống nhiều bậc của đất ngập nước dòng chảy ngầm. Do đó, sự kết hợp giữa bể cấp khí và không cấp khí có thể mang lại hiệu suất xử lý nitơ trong nước thải tốt hơn.

Bảng 4. Nồng độ các chỉ tiêu trong nước thải sau xử lý của bể LSH có cấp không khí và không cấp không khí

\begin{tabular}{|c|c|c|c|c|c|c|}
\hline \multirow[t]{2}{*}{ Thông số } & \multirow[t]{2}{*}{ Đơn vị } & \multicolumn{2}{|c|}{$\begin{array}{c}\text { Thí nghiệm cấp không khí } \\
(\mathrm{n}=3)\end{array}$} & \multicolumn{2}{|c|}{$\begin{array}{c}\text { Thí nghiệm không cấp } \\
\text { không khí }(n=3)\end{array}$} & \multirow{2}{*}{$\begin{array}{r}\text { QCVN } \\
14: 2008 / \text { BTNMT } \\
\text { (cột A) } \\
\end{array}$} \\
\hline & & HRT $=5 \mathrm{~h}$ & HRT $=6 \mathrm{~h}$ & HRT $=6 \mathrm{~h}$ & HRT $=8 \mathrm{~h}$ & \\
\hline $\mathrm{pH}$ & - & $7,2 \pm 0,07$ & $7,4 \pm 0,07$ & $6,3 \pm 0,2$ & $6,3 \pm 0,1$ & $5-9$ \\
\hline DO & $\mathrm{mg} / \mathrm{L}$ & $2,6 \pm 0,1$ & $2,67 \pm 0,12$ & 0 & 0 & - \\
\hline TSS & $\mathrm{mg} / \mathrm{L}$ & $7,4 \pm 0,4$ & $7,18 \pm 0,4$ & $10,7 \pm 1,8$ & $9,6 \pm 0,7$ & 50 \\
\hline $\mathrm{BOD}_{5}$ & $\mathrm{mg} / \mathrm{L}$ & $17,9 \pm 1,9$ & $13,3 \pm 0,6$ & $31,6 \pm 4,6$ & $21,5 \pm 2,5$ & 30 \\
\hline COD & $\mathrm{mg} / \mathrm{L}$ & $40,2 \pm 2,1$ & $29,1 \pm 3,3$ & $69,6 \pm 1,3$ & $44,7 \pm 4,9$ & $75(*)$ \\
\hline TKN & $\mathrm{mg} / \mathrm{L}$ & $16,2 \pm 6,1$ & $14,3 \pm 1,6$ & $19,4 \pm 1,7$ & $15,2 \pm 0,9$ & - \\
\hline $\mathrm{N}-\mathrm{NH}_{4}{ }^{+}$ & $\mathrm{mg} / \mathrm{L}$ & $14,4 \pm 1,4$ & $9,5 \pm 0,5$ & $15,9 \pm 1,2$ & $14,3 \pm 1,3$ & 5 \\
\hline $\mathrm{N}-\mathrm{NO}_{3}{ }^{-}$ & $\mathrm{mg} / \mathrm{L}$ & $4,9 \pm 0,28$ & $5,8 \pm 0,6$ & $0,33 \pm 0,12$ & $0,4 \pm 0,14$ & 30 \\
\hline $\mathrm{TP}$ & $\mathrm{mg} / \mathrm{L}$ & $0,51 \pm 0,12$ & $0,21 \pm 0,07$ & $1,8 \pm 0,5$ & $1,6 \pm 0,4$ & $4(*)$ \\
\hline $\mathrm{P}_{-} \mathrm{PO}_{4}{ }^{3-}$ & $\mathrm{mg} / \mathrm{L}$ & $0,31 \pm 0,09$ & $0,06 \pm 0,03$ & $0,22 \pm 0,07$ & $0,17 \pm 0,03$ & 6 \\
\hline
\end{tabular}

Ghi chú: (*) QCVN 40:2011/BTNMT (cột A)

( $n=3$ ): nuớc thải sau xủ̉ lý được thu thập trong 3 đọt

\section{4. Ảnh hưởng thời gian lưu nước đến hiệu suất xử lý}

\subsubsection{Thí nghiệm cấp không khi}

Thời gian lưu nước trong bể LSH là một yếu tố tác động đến hiệu suất loại bỏ các chất ô nhiễ̃m trong nước thải. Hình 3 trình bày hiệu suất xử lý của bể LSH có cấp không khí với HRT khác nhau. Kết quả nghiên cứu cho thấy rằng hiệu suất xử lý tỷ lệ thuận với HRT, cụ thể, khi HRT kéo dài từ 5 giờ lên 6 giờ thì hiệu suất xử lý $\mathrm{COD}$ tăng lên $3 \%$ và $\mathrm{BOD}_{5}$ tăng lên $4 \%$. Hiệu suất xử lý các chỉ tiêu nitơ và phosphor gia tăng và khác biệt có ý nghĩa $(\mathrm{p}<0,05)$, trong đó TKN tăng $16 \%, \mathrm{~N}^{-N_{4}}{ }_{4}^{+}$tăng $11,2 \%$, TP tăng $13 \%$ và $\mathrm{P}-\mathrm{PO}_{4}{ }^{3-}$ tăng $8,5 \%$.

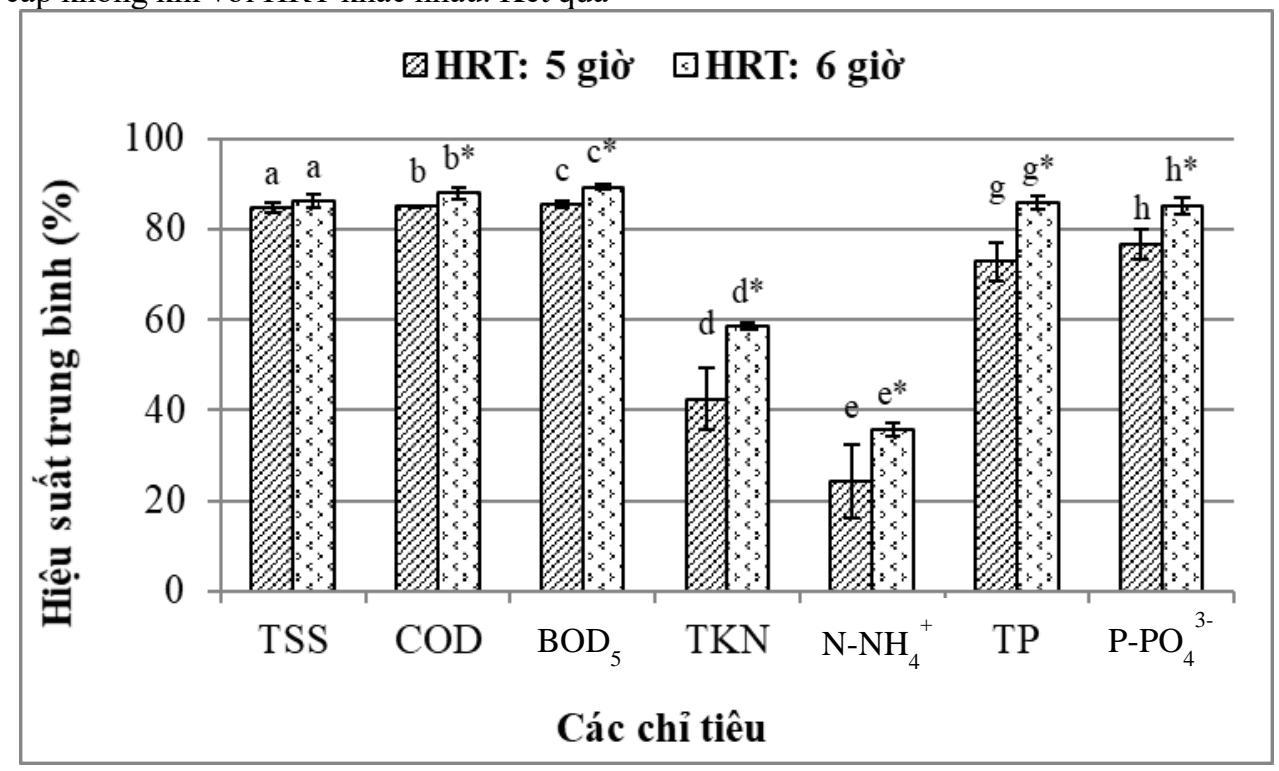

Hình 3. Hiệu suất xử lý của thí nghiệm cấp không khí với HRT 5 giờ và 6 giờ 


\subsubsection{Thí nghiệm không cấp không khí}

Hình 4 thể hiện hiệu suất xử lý của bể LSH với lớp giá thể ống hút nhựa ngập trong nước không cung cấp ôxy với HRT 6 giờ và 8 giờ. Tương tự như bể LSH có cấp khí, khi HRT tăng thì hiệu suất loại bỏ các chất ô nhiễm tăng theo. Hai chỉ tiêu có hiệu suất xử lý tăng trên $10 \%$ gồm $\mathrm{COD}$ và $\mathrm{N}-\mathrm{NO}_{3}$. Trong hệ thống không cấp không khí, vì lượng oxygen hòa tan vào nước thấp $(<0,5 \mathrm{mg} / \mathrm{L})$ nên nó phù hợp cho sự phát triển của các vi sinh vật khử N-
$\mathrm{NO}_{3}^{-}$. Đây là những vi sinh vật có tốc độ sinh trưởng chậm nên việc tăng HRT sẽ giúp cho các vi sinh vật có thời gian hấp thu chất dinh dưỡng tốt hơn. Kết quả của nghiên cứu này cho thấy rằng bể LSH không

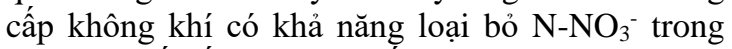
nước thải rất tốt với hiệu suất đạt $64 \%$ ở HRT 8 giờ.

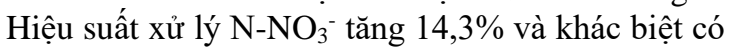
ý nghĩa $(\mathrm{p}<0,05)$ khi tăng HRT từ 6 giờ lên 8 giờ. Nghiên cứu của Albuquerque et al. (2012) cho thấy quá trình nitrate hóa và khử nitrate trong bể LSH diễn ra khi DO dao động khoảng 0,4-0,8 mg/L.

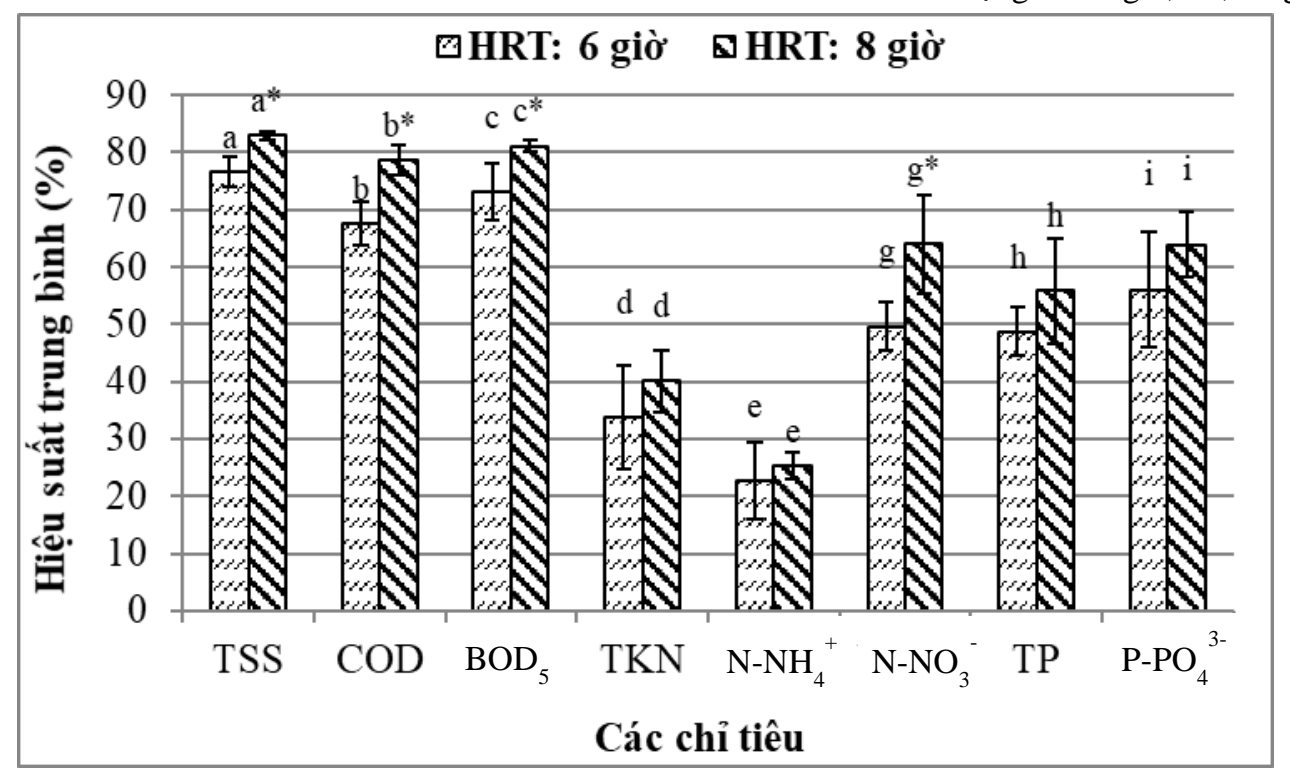

\section{Hình 4. Hiệu suất xử lý của thí nghiệm không cấp không khí với HTR 6 giờ và 8 giờ}

\subsection{So sánh hiệu suất xử lý của LSH có cấp và không cấp không khí}

Hình 5 thể hiện hiệu suất xử lý của bể LSH có cấp không khí và không cấp không khí có cùng HRT 6 giờ. Nhìn chung, hiệu suất xử lý của bể LSH có cấp không khí đều cao hơn bể LSH không cấp không khí. Cụ thể, hiệu suất loại bỏ COD và BOD cao hơn $15,1 \%$ và $22,1 \%$. Các chỉ tiêu dinh dưỡng gồm $\mathrm{TKN}, \mathrm{N}-\mathrm{NH}_{4}{ }^{+}, \mathrm{TP}$ và $\mathrm{P}_{-} \mathrm{PO}_{4}{ }^{3-}$ cũng cao hơn lần lượt là $25,5 \%, 17,7 \%, 37,8$ và $31,2 \%$. Tuy nhiên, quá trình khử $\mathrm{N}^{-\mathrm{NO}_{3}}{ }^{-}$trong bể LSH có cấp không khí không hiệu quả so với bể LSH không cấp không khí.

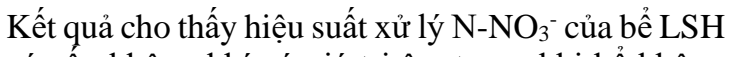
có cấp không khí có giá trị âm trong khi bể không cấp không khí đạt hiệu suất $44,4 \%$. Điều này cho thấy rằng tốc độ nitrate sinh ra trong bể LSH có cấp không khí cao hơn tốc độ chất này bị khử. Kết quả nghiên cứu trước đây cho thấy rằng sự hạn chế sục khí thúc đẩy khả năng loại bỏ nitơ trong nước thải nhưng ngược lại hiệu suất xử lý $\mathrm{BOD}_{5}$ giảm xuống (Albuquerque et al., 2012). Bên cạnh đó, ngoài các yếu tố vi sinh chuyê̂n hóa đạm, tải nạp nitơ và tỷ lệ $\mathrm{NO}_{3}{ }^{-} / \mathrm{NH}_{4}{ }^{+}$cũng tác động đến hiệu suất loại bỏ nitơ trong hệ thống LSH (Albuquerque et al., 2012; Yue et al., 2018). 


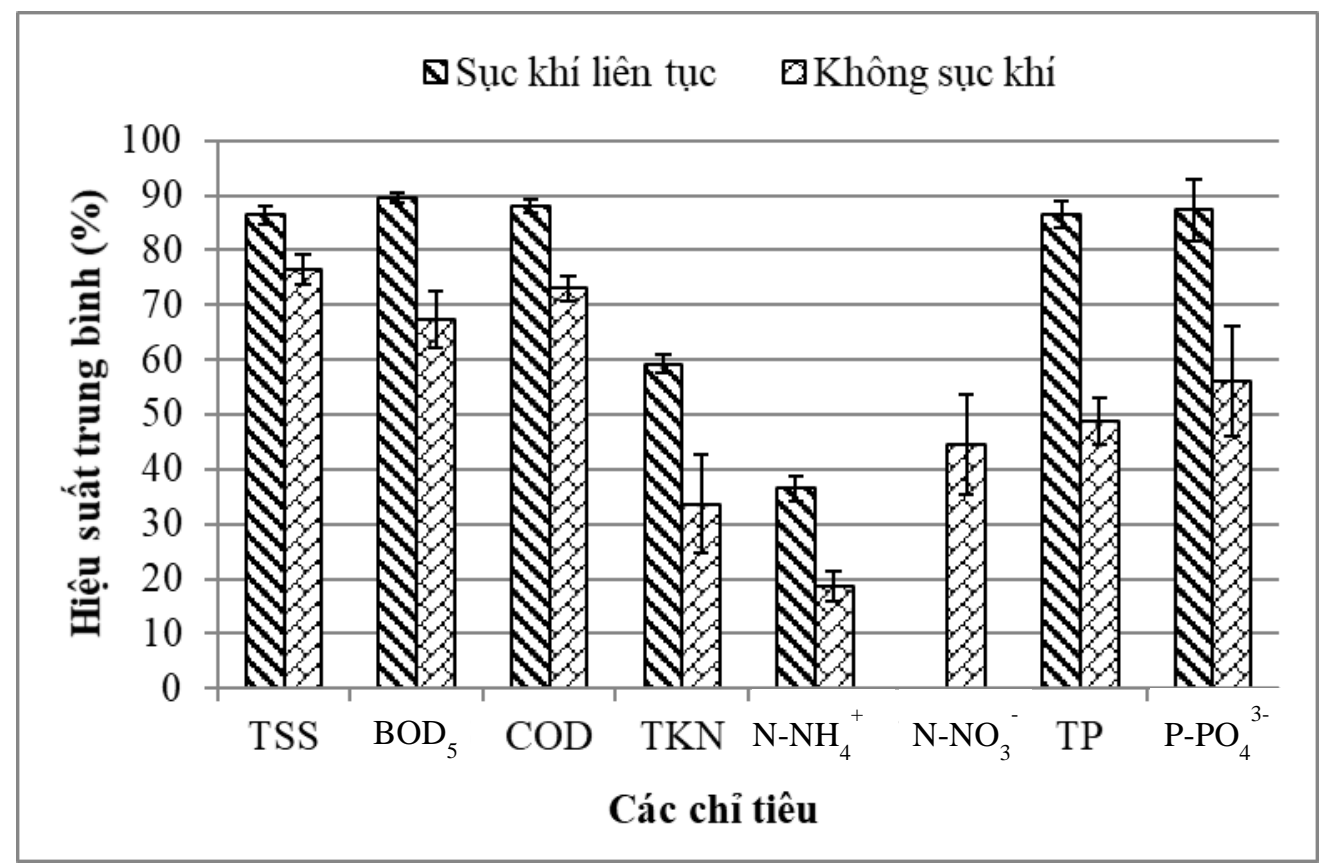

Hình 5. Hiệu suất xử lý của cột LSH có cấp không khí và không cấp không khí

\section{KẾT LUẬN}

Mô hình bể LSH sử dụng giá thể ống hút nhựa ngập nước vận hành trong điều kiện cấp khí và không cấp khí có thể loại bỏ hầu hết các chất ô nhiễm trong NTSH. Chất lượng nước sau xử lý của bể LSH có cấp khí với HRT 5 giờ và 6 giờ và bể LSH không cấp khí với HRT 8 giờ đều đạt QCVN 14:2008/BTNMT (cột A) đối với các chỉ tiêu pH, TSS, $\mathrm{BOD}_{5}, \mathrm{COD}, \mathrm{N}^{-\mathrm{NO}_{3}}{ }^{-}$, TP, $\mathrm{P}-\mathrm{PO}_{4}{ }^{3-}$. Tuy nhiên, chỉ tiêu $\mathrm{N}^{-\mathrm{NH}_{4}}{ }^{+}$chỉ đạt cột $\mathrm{B}$ QCVN 14:2008/BTNMT đối với bể LSH có cấp khí ứng với HRT 6 giờ và cao hơn qui chuẩn đối với các thí nghiệm còn lại. Khi HRT trong các bể LSH dài hơn thì hiệu suất xử lý chất ô nhiễm tăng. Quá trình cấp khí và không cấp khí vào bể LSH cũng tác động đến hiệu suất loại bỏ chất ô nhiễm. Kết quả cho thấy bể LSH cấp không khí có hiệu suất xử lý các chất ô nhiễm cao hơn bể không cấp không khí ngoại trừ chỉ

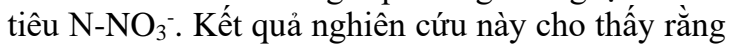
ống hút nhựa có thể tái sử dụng làm giá thể màng sinh học trong mô hình LSH để xử lý nước thải đồng thời góp phần giảm thiểu rác thải nhựa và bảo vệ môi trường.

\section{LÒ̀I CẢM TẠ}

Nghiên cứu này được tài trợ bởi Dự án Nâng cấp Trường Đại học Cần Thơ VN14-P6 bằng nguồn vốn vay ODA từ chính phủ Nhật Bản.

\section{TÀI LIỆU THAM KHẢO}

Albuquerque, A., Makinia, J., \& Pagilla, K. (2012). Impact of aeration conditions on the removal of low concentrations of nitrogen in a tertiary partially aerated biological filter. Ecological Engineering, 44, 44-52.

APHA (2005). Standard Methods for the Examination of Water and Wastewater. American Public Health Association (21 $\left.{ }^{\text {st }} \mathrm{ed}\right)$. Washington DC.

Bộ Tài nguyên và Môi trường. (2018). Báo cáo hiện trạng môi trường quốc gia năm 2018, chuyên đề "Môi trưòng nước các lưu vực sông. http://dwrm.gov.vn/index.php?language=vi\&nv= download\&op=Sa-ch-Ta-i-lieu-tham-kha-o/Baocao-hien-trang-moi-truong-quoc-gia-nam-2018Chuyen-de-Moi-truong-nuoc-luu-vuc-song

Etnyre L.M. (1989). Finding Oil and Gas from Well Logs. Springer US. ISBN 978-1-4757-5232-8.

Gajewska, M., Skrzypiec, K., Jóźwiakowski, K., Mucha, Z., Wójcik, W., Karczmarczyk, A., \& Bugajski, P. (2020). Kinetics of pollutants removal in vertical and horizontal flow constructed wetlands in temperate climate. Science of The Total Environment, 718, 137371. https://doi.org/10.1016/j.scitotenv.2020.137371

Geyer, R., Jambeck, J., Law, K. (2017). Production, use, and fate of all plastics ever made. Science Advances, 3(7), 1-5. DOI: 10.1126/sciadv.1700782

Gutierrez, J. N., Royals, A. W., Jameel, H., Venditti, R. A., and Pal, L. (2019). Evaluation of paper 
straws versus plastic straws: Development of a methodology for testing and understanding challenges for paper straws, BioRes, 14(4), 83458363. DOI: $10.15376 /$ biores.14.4.8345-8363

Jenna R. J., Roland G., Chris W., Theodore R. S., Miriam P., Anthony A., Ramani N., Kara L.L. (2015). Plastic waste inputs from land into the ocean. Science 347,768 . DOI: 10.1126/science. 1260352

Lê Hoàng Việt, Nguyễn Võ Châu Ngân, Tạ Hoàng Hộ, \& Nguyễn Văn Phủ. (2015). Hiệu quả xử lý nước thải chế biến thủy sản bằng bể LSH hiếu khí ngập nước. Tạp chí Khoa học Truờng Đại hoc Cần Tho. Số chuyên đề: Môi truờng và Biến đổi khí hạu, 94-101.

Nguyễn Văn Phước. (2014). Giáo trình xủ lý nước thải bằng phương pháp sinh hoc. Nhà xuất bản Đại học Quốc gia Thành phố Hồ Chí Minh. ISBN:978-604-73-2718-8.

Nguyễn Thị Thanh Phượng, Nguyễn Văn Phước, \& Thiệu Cẩm Anh. (2010). Nghiên cứu đánh giá hiệu quả xử lý nước thải tinh bột mì bằng công nghệ LSH hiếu khí trên các loại vật liệu khác nhau. Tạp chí Phát triển KH\&CN, 13(M2), 54-66.

Oliveira, G.A., Colares, G.S., Lutterbeck, C.A., Dell'Osbel, N., Machado, Ê.L., Rodrigues, L.R. (2021). Floating treatment wetlands in domestic wastewater treatment as a decentralized sanitation alternative. Science of The Total Environment, 773, 145609.

Osorio, F. \& Hontoria, E. (2002). Wastewater treatment with a double-layer submerged biological aerated filter, using waste materials as biofilm support. Journal of Environmental Management, 65(1), 79-84.

Phạm Thị Hồng Ngân \& Phạm Khắc Liệu. (2012). Đánh giá khả năng xử lý nước thải nuôi trồng thủy sản nước lợ của bể LSH hiếu khí có lớp vật liệu ngập nước. Tạp chí khoa hoc Đại hoc Huế, 74B(5), 113-122.

Science for Environment Policy. (2011). Plastic waste: ecological and human health impacts. DG environment news alert service. European Commission, Brussels.

Tổng cục Môi trường. (2019). Quản lý chất thải nhựa và túi ni lông tại Việt Nam. https://optoce.no/wpcontent/uploads/2019/10/VEA-Quan-ly-chatthai-nhua-va-tui-nilong.pdf

Yue, X., Yu, G., Lu, Y., Liu, Z., Li, Q., Tang, J., \& Liu, J. (2018). Effect of dissolved ôxygen on nitrogen removal and the microbial community of the completely autotrophic nitrogen removal over nitrite process in a submerged aerated biological filter. Bioresource Technology, 254, 67-74. 